\title{
Lactose intolerance: myths and facts. An update
}

a. Consultorios Médicos Pediátricos, Ramos Mejía, Argentina.

b. Department of Nutrition and Diet Therapy, Hospital de Niños Sor María Ludovica, La Plata, Argentina.

c. Department of Pediatric Gastroenterology and Hepatology, Hospital Italiano de Buenos Aires, Autonomous City of Buenos Aires, Argentina.

d. Sanatorio de Niños de Rosario, Rosario, Argentina.

e. Institute of Industrial Dairy Science (National Scientific and Technical Research Council [Consejo Nacional de Investigaciones Científicas y Técnicas, CONICET]Universidad Nacional del Litoral [UNL]), School of Chemical Engineering, Universidad Nacional del Litoral, Santa Fe, Argentina.

E-mail address:

María del Carmen Toca: mtoca@intramed.net

Funding:

Nutricia Bagó provided

the place to carry out meetings and helped to develop the charts. Nutricia Bagó did not have any participation in the writing of this article and did not interfere with the editorial management. None of the authors has a business relationship with Nutricia Bagó, except for their participation in conferences organized by the company and other events organized by other companies.

\section{Conflict of interest:}

None.

Received: 4-6-2021

Accepted: 7-21-2021

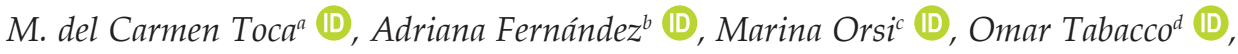 Gabriel Vinderola ${ }^{(1 D}$}

\begin{abstract}
Lactose is the main carbohydrate presentinhuman milk. It is a disaccharide made up of glucose and galactose. It is produced in the mammary glands, regardless of maternal diet. In addition to providing energy, it is the only source of dietary galactose, necessary for macromolecule synthesis, including oligosaccharides, glycoproteins, and glycolipids. It favors calcium, magnesium, and zinc absorption and retention. Its digestion by lactase and subsequent absorption occurs in the small intestine. Lactase deficiency may be classified into congenital primary (very rare), late-onset primary or secondary due to an injury of the intestine; it may cause intolerance with pain, abdominal distension, abdominal gas, and diarrhea. In the colon, it may be hydrolyzed by bifidobacteria and lactobacilli. The nutritional management of intolerance should always preserve breastfeeding. Lactose reduction or elimination should be transient, and eliminated food should be replaced with other similar in calorie, protein, mineral, and vitamin content. Key words: lactose, human milk, lactase, microbiota, lactose intolerance.
\end{abstract}

http: / / dx.doi.org/ 10.5546/ aap.2022.eng.59

To cite: Toca MC, Fernández A, Orsi M, Tabacco O, Vinderola G. Lactose intolerance: myths and facts. An update. Arch Argent Pediatr 2022;120(1):59-66.

\section{INTRODUCTION}

Lactose is a major component of human milk. It is the main carbohydrate and source of energy in most mammalian milks and, as such, it has been an important component of human diet since the origin of humanity. ${ }^{1}$ Lactose is a disaccharide made up of 2 monosaccharides: galactose and glucose. They are joined by a $\beta-1-4$ glycosidic linkage, a bond between carbon 1 of galactose and carbon 4 of glucose. Hydrolysis of such bond requires a specific enzyme called lactase or $\beta$-galactosidase for the subsequent absorption of monosaccharides in the small intestine. Intestinal lactase activity peaks at birth and reduces progressively with weaning; it persists until adulthood only in some subjects. Globally, 35\% of the adult population has lactase persistence, with a large variability across different geographic regions, depending on dietary culture, with a persistence of up to $90 \%$ in the Nordic populations versus $10 \%$ in South-East Asia. ${ }^{2}$ There are no data about lactase persistence in Argentina.

Studies published in recent years have modified the concepts about the nutritional relevance of lactose, its production, digestion, and absorption. ${ }^{1}$ Investigations about lactase activity before and after lactose-containing and lactosefree diets, genetic testing, and gut microbiota studies in lactase persistent and lactase non-persistent populations are part of these advances. ${ }^{1,2}$

In spite of such new knowledge, the "adverse effects" have become more popular than the benefits, and they are usually wrongly attributed to adverse gastrointestinal symptoms. ${ }^{1-4}$ This leads to changes in eating habits, the elimination of lactose for prolonged periods, even interrupting 
breastfeeding, and the avoidance of dairy products from an early age to adulthood, based on no evidence to support it. Such fear to adverse effects in the early stages of life may generate a habit towards the reduction or elimination of dietary dairy product intake in children and adolescents, with an adverse impact on normal growth because an adequate milk intake at an early age provides energy, proteins of high biological value, vitamin $\mathrm{D}$, vitamin B12, and calcium.

In order to clarify the clinical and nutritional relevance of lactose and lactase activity over life, describe the advances made in the pathophysiology of lactose intolerance and the knowledge about the importance of gut microbiota to make better decisions about management strategies, a group of specialists in pediatrics, nutrition, gastroenterology, and microbiology gathered to review the available bibliography and discuss and write this document.

\section{LACTOSE LEVELS IN HUMAN MILK, COW'S MILK, AND INFANT FORMULAS}

Lactose is the main and only digestible carbohydrate in human milk (HM) and other mammalians (cow, sheep, and goat) milk. Its levels vary across the different species.

In $\mathrm{HM}$, lactose accounts for $90 \%$ of carbohydrates, with approximately $7 \mathrm{~g} / 100 \mathrm{~mL}$, which means $40 \%$ of calorie intake. Lactose levels tend to increase over the course of breastfeeding.

Cow's milk contains $4.6 \mathrm{~g} / 100 \mathrm{~mL}$. First infant formulas contain 5.4-8.2 g/100 mL of lactose (between 9.0 and $14.0 \mathrm{~g} / 100 \mathrm{kcal}$ as per the Codex Alimentarius). ${ }^{5}$ Follow-on formulas have a lower lactose content and the same amount of carbohydrates because, according to the Codex Alimentarius, up to $30 \%$ may be maltodextrins.

\section{RELATIONSHIP BETWEEN LACTOSE PRODUCTION IN THE MAMMARY GLAND AND MATERNAL DIET}

Mammary gland cells synthesize lactose within the Golgi complex from the glucose that comes from the blood flow and is released into the alveolar lumen together with proteins. Lactose synthesis involves the action of the synthase enzyme, which is made up of 2 units: the alphalactalbumin sub-unit, a milk serum protein, and galactosyltransferase. During gestation, lactalbumin remains inactive, but at the time of birth, prolactin stimulates its activity. Its production is independent from the consumption of lactose-containing dairy products in the maternal diet.

Lactose secretion increases intra-alveolar osmotic pressure due to the accumulation of diluted substances in relation to the outside, where blood flows. As a result, water flows from the outside blood to the alveolar lumen. Therefore, lactose regulates the amount of water drawn into the alveoli and, as a consequence, the volume of milk produced. This maintains lactose content in human milk that warrants its flow and a low osmolarity, similar to that of maternal plasma. Lactose provides $60 \%$ of human milk osmolarity. ${ }^{6}$

\section{BENEFITS OF LACTOSE CONSUMPTION}

Lactose offers multiple benefits for infant health and is also a major source of energy. Its components (glucose-galactose) are involved in the production of different macromolecules (oligosaccharides, glycoproteins, and glycolipids).

Lactose has a modulatory effect in the intestine and its hydrolyzation into monosaccharides has a rehydrating effect in the small intestine because the active absorption of glucose is accompanied by sodium and water. ${ }^{7}$ It is the main source of the more complex oligosaccharides in $\mathrm{HM}$ with prebiotic functions. ${ }^{8,9}$

Different animal studies compared lactosecontaining and lactose-free infant formulas and demonstrated that a better calcium absorption was associated with dietary lactose intake. ${ }^{10,11}$ One of the proposed mechanisms is the reduction of the $\mathrm{pH}$ resulting from its fermentation in the intestinal lumen, thus increasing calcium solubility and absorption. A better zinc and magnesium absorption was also demonstrated in association with lactose content. However, studies conducted in humans have not confirmed these findings. ${ }^{12,13}$

\section{SWEETENING AND CARIOGENIC CHARACTERISTICS OF LACTOSE}

Lactose has a lower glycemic index and a lower sweetening and cariogenic effect than other carbohydrates. ${ }^{14-16}$

Its lower sweetening effect is beneficial for the development of infants' eating choices. Unlike sucrose or maltodextrin, lactose does not cause rewarding effects on the central nervous system.

\section{THE RELEVANCE OF GALACTOSE}

Lactose is the only source of dietary galactose. ${ }^{1,17}$ Galactose is critical for the human 
metabolism, not only because of its role as a source of energy, but also in the production of macromolecules, such as galactocerebrosides, gangliosides, and mucoproteins, which make up nervous cell membranes. Therefore, galactose has a direct relationship with early neurodevelopment. ${ }^{18}$

Approximately $80 \%$ of galactose intake is deposited in the liver and becomes a major source of movable energy. The remaining 20\% is transported to other organs and tissues, such as the brain, to produce amino acids, or to the mammary gland to produce lactose in HM. ${ }^{19}$

\section{EFFECTS OF LACTOSE ON THE GUT MICROBIOTA}

Lactose plays a critical nutrient role in the gut microbiota at an early age because it is a structural portion of HM oligosaccharides (HMO). The more than $200 \mathrm{HMO}$ described to date share a common denominator: they all contain a lactose core in each of their molecules..$^{20}$ Bifidobacterium species, such as Bifidobacterium breve, B. infantis, B. longum, and B. lactis, ${ }^{21}$ are capable of releasing lactose from certain HMO through the action of $\beta$-hexosaminidase, which is subsequently hydrolyzed by $\beta$-galactosidase (bacterial lactase) by lactobacilli and bifidobacteria in its component sugars: glucose and galactose. ${ }^{22}$ It has been demonstrated that the oral administration of lactose can significantly increase the intestinal population of lactobacilli and bifidobacteria. ${ }^{23}$

In addition, in vitro studies have shown that lactose induces the expression of the CAMP gene (cathelicidin antimicrobial peptide), which encodes the only human cathelicidin (antimicrobial peptide) in colon epithelial cells, regardless of the dosage and duration. That study suggested an additional effect on innate immunity through the positive regulation of gastrointestinal antimicrobial peptides, which may lead to the protection of the neonatal intestine against pathogens and to the regulation of the infant microbiota. ${ }^{24}$

\section{LACTOSE DIGESTION AND ABSORPTION}

The small intestine is capable of absorbing monosaccharides only, so lactose hydrolysis is necessary. This is carried out by the lactase enzyme (also known as $\beta$-galactosidase), which is expressed on the surface of epithelial brush border cells of the small intestine. They are highly abundant in the proximal portion of the jejunum and decrease towards the ileum. ${ }^{2}$ Hydrolysis products (glucose and galactose) are absorbed into the apical pole of enterocytes: glucose, mostly in the active form together with sodium and water absorption; and galactose, through facilitators.

\section{LACTASE ACTIVITY AT BIRTH AND OVER LIFE}

Intestinal lactase activity can be detected in the fetal intestine at 8 weeks of gestation, and increases significantly between weeks 24 and $40 .{ }^{1,2,25}$ After the first feeding with HM, lactase activity increases rapidly to promote lactose digestion; it achieves over $98 \%$ of efficiency in the first 5 days of life. ${ }^{25}$ Shulman et al. demonstrated that preterm babies receiving early enteral feeding showed a greater enzyme activity $(100 \%)$ than in those were feeding was delayed $(60 \%)$ and that, at 10 days of life, lactase levels were higher in breastfed infants than in those who received infant formula. ${ }^{26}$ In spite of such "relative lactase deficiency" among preterm infants, clinical symptoms of intolerance are uncommon and lactose intake is not contraindicated. ${ }^{2}$

Lactase content and persistence of lactase activity over life in the small intestine of mammals are genetically regulated, but epigenetic mechanisms that have not been completely elucidated yet may modify phenotypic expression. A frequent observation is that lactase activity reduces progressively since 1 year old, together with the lower need of dairy products as a dietary source of energy in children. As of this age, a population group will persist with lactase activity, while other group will completely lose it. ${ }^{1,2,27,28}$ The persistence of lactase activity is a strong and positive genetic trait selected over the course of evolution. Currently, approximately $35 \%$ of the adult population has lactase persistence. ${ }^{1,2,28}$

\section{LACTASE DEFICIENCY. RELATIONSHIP WITH LACTOSE CONSUMPTION}

The reduced ability to digest lactose varies from one person to the other, but it is worth noting that enzyme activity cannot be induced from a higher substrate intake. The current opinion is that, once lactase activity fully establishes, it is no longer affected by dietary and/ or lactose intake changes. . $^{1,27,28}$

\section{TYPES OF LACTASE DEFICIENCY Lactose intolerance}

The factors with an impact on lactose tolerance 
are digestive capacity, lactase levels in the enterocyte, the rate at which it enters the intestinal lumen, the integrity of the villi structure, the host's microbiota, and colon function. ${ }^{30}$ Lactose that is not hydrolyzed at or absorbed into the small intestine reaches the colon and is fermented by the bacteria living there. They may be healthy bacteria producing metabolites that are beneficial for the host or, more distally, bacteria producing gases, such as hydrogen, carbon dioxide, and methane $\left(\mathrm{H}_{2}\right.$, $\mathrm{CO}_{2}$, and $\mathrm{CH}_{4}$ ), and harmful metabolites.

"Intolerant" individuals are those who have symptoms caused by a poor digestion and malabsorption of lactose. The clinical condition may develop between 30 minutes and 2 hours after intake, and is characterized by diarrhea caused by the presence of lactose in the intestinal lumen, which generates osmotic pressure and attracts water to the intestinal lumen, with softliquid stools and accelerated intestinal transit. Fermentation causes gases, which in turn cause abdominal distension and pain, cramps and/or postprandial fullness, burping, nausea, and acid stools accompanied by perianal erythema (Table 1 and Figure 1).27,30

\section{Secondary lactase deficiency}

Secondary lactase deficiency is caused by damage at the intestinal epithelium, which may occur in children with rotavirus gastroenteritis, parasitic disease (Giardia lamblia), intestinal disease due to cow's milk protein allergy, celiac disease, Crohn's disease, AIDS, malnutrition or lack of absorption surface, as in the case of short bowel syndrome.

The absence of lactase activity is transient and reversible, i.e., it will improve once the underlying intestinal damage is resolved..$^{27,30}$
Diagnostic clinical tests and histological exams are available to confirm the different types of lactase deficiency with lactose intolerance symptoms (Table 2).

\section{GUT MICROBIOTA AND MECHANISMS OF COLONIC ADAPTATION}

Bifidobacterium and Lactobacillus species have bacterial lactase that allows them to digest and use lactose as a source of energy. Fermentation produces beneficial short-chain fatty acids (SCFA), including butyric acid, an important source of energy for the colonic epithelium, but does not produce gases like hydrogen and methane, as in the case of other heterofermentative bacteria living in the colon (Figure 2). In turn, it has been demonstrated that regular lactose intake stimulates the growth of these beneficial bacteria as a prebiotic effect.

Some lactose intolerant individuals usually state that they have less severe and less frequent gastrointestinal symptoms as they gradually and progressively introduce lactose-containing food. This suggests that some adaptation mechanisms related to lactose processing are produced during the progressive and sustained intake of this disaccharide.

This process is known as "colonic adaptation" to lactose-containing food and seems to be reversible, i.e., once lactose is eliminated from the diet, adaptation disappears gradually, which in turn may cause intolerance symptoms once lactose is re-introduced. ${ }^{2}$

\section{THE ROLE OF BIOTICS AND FERMENTED FOODS}

HM contains lactose, oligosaccharides (which act as prebiotics), and bacteria, which warrants an

TABLE 1. Types of lactase deficiency

\begin{tabular}{ll}
\hline Congenital primary lactase deficiency & $\begin{array}{l}\text { Autosomal recessive disease. Rare. Absent or reduced lactase activity since } \\
\text { birth, causes severe diarrhea, acidosis, and hypercalcemia. }{ }^{27,29,30}\end{array}$ \\
Early primary lactase deficiency & $\begin{array}{l}\text { Reduced lactase activity at birth. Transient, more common in preterm infants, } \\
\text { reversible with feeding, especially breastfeeding. }\end{array}$ \\
Late-onset or adult-type primary lactase deficiency & $\begin{array}{l}\text { Autosomal recessive genetic expression. May start at } 5-6 \text { years old or during } \\
\text { adolescence. Irreversible, slow and progressive onset, observed in } 65 \% \text { of the } \\
\text { worldwide adult population (LNP). }{ }^{1,2,27,28,30}\end{array}$ \\
Secondary lactase deficiency & $\begin{array}{l}\text { Loss of activity due to damaged villi in the small intestine. May occur at } \\
\text { any age, in LP or LNP subjects. Reversible with treatment of intestinal } \\
\text { injury. } 1,2,27,30\end{array}$ \\
\hline
\end{tabular}


early gut colonization with a healthy microbiota and a colonic adaptation that will allow to reduce the symptoms of a poor lactose digestion.

If breastfeeding is not possible, adding prebiotics, probiotics, symbiotics, and postbiotics to infant formula may be a strategy to promote a healthier intestinal environment to ensure a better recovery. There are different levels of scientific evidence about the effectiveness of each of these biotics.

Savaiano et al., demonstrated that regular prebiotic (galacto-oligosaccharides) intake improves symptoms and results of the hydrogen breath test. ${ }^{31}$ However, the benefit of the direct use of probiotics for the management of lactose intolerance is still controversial because 2 systematic reviews have shown conflicting results. ${ }^{32-34}$

The beneficial effect is observed in fermented products, such as yogurt. The benefit in lactose intolerant subjects is based on the presence of endogenous lactase activity by the microorganisms present in yogurt (Streptococcus thermophilus and Lactobacillus bulgaricus). In addition, given its higher osmolarity, density, and viscosity, yogurt delays gastric emptying and intestinal transit, which leads to a slower, gradual contribution of lactose to the intestine, thus
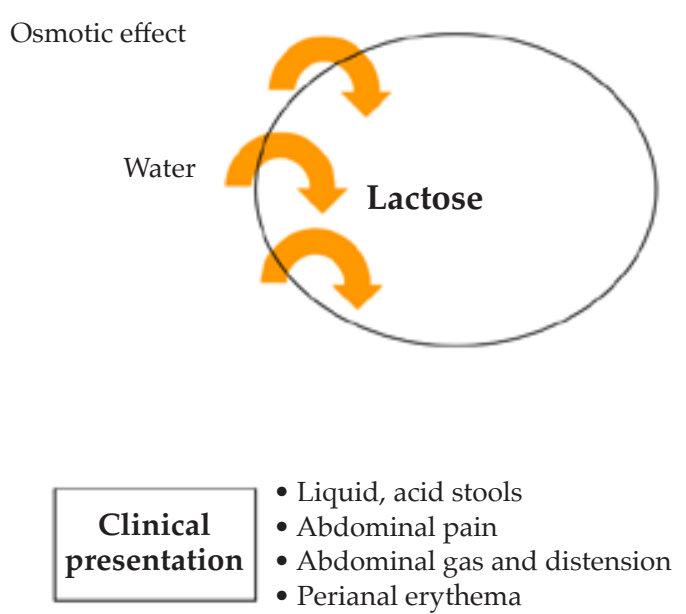



Acid stools

Intolerance symptoms are caused by the osmotic effect of lactose on the intestinal lumen and by the fermentation effect of colonic bacteria that produce gases, such as hydrogen, carbon dioxide, and methane $\left(\mathrm{H}_{2^{\prime}} \mathrm{CO}_{2^{\prime}}\right.$ and $\left.\mathrm{CH}_{4}\right)$, acid and harmful metabolites. $\mathrm{H}_{2}$ : hydrogen; $\mathrm{CO}_{2}$ : carbon dioxide; SCFA: short-chain fatty acids.

Source: Developed by the authors.

TABLE 2. Diagnosis of lactose intolerance

Congenital primary lactase deficiency

Genetic test or upper gastrointestinal endoscopy, with intestinal biopsy collection and subsequent measurement of lactase activity per gram of tissue in the duodenal mucosa. ${ }^{29,30}$

Late-onset or adult-type primary lactase deficiency Secondary lactase deficiency

1. Test with intake elimination and clinical response. Non-specific. May be useful in a secondary type case with a clear etiologic diagnosis. ${ }^{1}$

2. Measurement of fecal reducing substances. Poorly specific. Other $\mathrm{CHO}$, such as $\mathrm{HMO}$, may generate reducing substances without causing symptoms. ${ }^{1}$

3. Hydrogen breath test: fast, non-invasive, and more specific. Measures hydrogen produced by colonic bacteria. ${ }^{1,27,30}$

4. Genetic test to diagnose late-onset primary lactase deficiency with the detection of a C/ T-13910 polymorphism (LNP). ${ }^{1,28,30}$ 
optimizing the action of residual $\beta$-galactosidase in the small intestine. ${ }^{35,36}$

\section{NUTRITIONAL MANAGEMENT OF INFANTS WITH LACTASE DEFICIENCY}

In newborn infants with congenital lactase deficiency, confirmed via intestinal biopsy, complete and permanent lactose elimination will be indicated.
Another absolute indication for lactose elimination is galactosemia. If such rare condition is the case, specific formulas should be indicated.

Breastfeeding should not be interrupted in infants with acute or prolonged diarrhea. Infants who are breastfed during diarrhea episodes have a lower loss and shorter disease duration than those in whom breastfeeding is interrupted. Human milk is the optimal food in health and

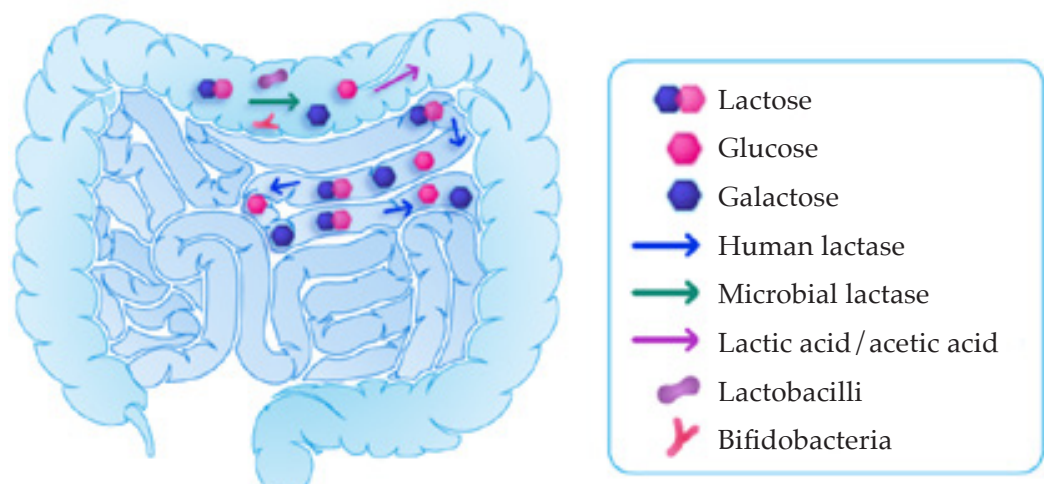

Most lactose that enters the digestive tract is hydrolyzed and absorbed in the proximal portion of the small intestine. When lactose escapes digestion in the small intestine, the colonic microbiota, especially lactobacilli and bifidobacteria, may contribute to lactose fermentation without causing abdominal gas. The colonic contribution to lactose metabolism will depend on each subject's microbiota composition.

Source: Developed by the authors.

Table 3. Lactose content every $100 \mathrm{~g}$ of food

\begin{tabular}{lll}
\hline Low content $\mathbf{( 0 - 2}$ g) & Medium content (2-5 g) & High content (>5 g) \\
\hline Margarine, butter & Yogurt & Cream \\
$\begin{array}{l}\text { Cheese: mozzarella, Parmesan, Gruyère, } \\
\text { blue cheese, Emmental, Brie, cheddar }\end{array}$ & White or fresh cheese, \\
Camembert & & Dairy ice cream \\
Low-lactose milk & & Cream cheese, cream cheese spread \\
& & Whole milk, semi-skimmed milk, \\
& & skimmed milk, powder milk, \\
& condensed milk, chocolate milk \\
\hline
\end{tabular}

Adapted from: Salas-Salvadó J. “Dieta controlada en lactosa.” In: Salas-Salvadó J. Nutrición y dietética clínica. 3d ed. Barcelona: Elsevier, 2014: 222.

TABLE 4. Nutritional components of cow's milk and plant-based beverages per serving

\begin{tabular}{lccccc}
\hline Beverage & Cal (kcal) & CHO (g) & Proteins $(\mathrm{g})$ & Fat $(\mathbf{g})$ & Calcium $(\mathbf{m g}) / \mathbf{v i t a m i n ~ D ~}(\mu \mathrm{g})$ \\
\hline Whole cow's milk & 114 & $9^{* *}$ & 6.8 & 6.5 & $230 / 2$ \\
*Rice-based & 59 & $8.2^{* * *}$ & 0 & 2.8 & $290 / 1$ \\
${ }^{*}$ Almond-based & 48 & $6.4^{* * *}$ & 1.1 & 2.1 & $291 / 1$ \\
*Soy-based & 80 & $8^{* * *}$ & 5.2 & 3 & $240^{*} / 2$ \\
\hline
\end{tabular}

CHO: carbohydrates.

* Supplemented with calcium and vitamin D.

** The main $\mathrm{CHO}$ is lactose.

*** The main $\mathrm{CHO}$ is sucrose. 
disease states, and should be promoted and maintained whenever possible. The benefits of $\mathrm{HM}$ should be weighed against the transient effects of lactose intolerance.

Most infants do not develop clinical signs or symptoms attributable to malabsorption due to lactase deficiency. Approximately $80 \%$ of infants with mild to moderate malnutrition, even those younger than 6 months, may tolerate milk with normal lactose levels without an increased risk for therapeutic failure.

Lactose reduction or elimination is only indicated as a transient measure in infants with severe malnutrition associated with severe intestinal disease.

Infant formulas reduced lactose contain approximately $1.6 \mathrm{~g} / 100 \mathrm{~mL}$ and those developed to relieve gastrointestinal disorders contain 3-4 g/100 mL. These and lactose-free formulas contain glucose polymers instead of lactose; the most common one is maltodextrin. The latter is rapidly digested, which results in an insulin response similar to that of glucose intake (glycemic index: 110). ${ }^{37}$

Plant-based alternatives should never be recommended because they do not contain an adequate amount of the nutrients required during childhood and adolescence. In addition, these products should not be referred to as "milk."

Lactose reduction should not be done at the expense of a reduced calorie intake, such as diluted milk.

\section{REFERENCES}

1. Romero Velarde E, Delgado Franco D, García Gutiérrez M, Gurrola Díaz C, et al. The importance of lactose in the human diet: Outcomes of a Mexican Consensus Meeting. Nutrients. 2019; 11(11):2737.

2. Forsgard RA. Lactose digestion in humans: intestinal lactase appears to be constitutive whereas the colonic microbiome is adaptable. Am J Clin Nutr. 2019; 110(2):273-9.

3. Vanderplas Y.Debates in allergy medicine: food intolerance does exist. World Allergy Organ J. 2015; 8:36.

4. Dreborg $S$. Debates in allergy medicine: food intolerance does not exist World Allergy Organ J. 2015; 8:37.

5. FAO-WHO. Standard for infant formula and formulas for special medical purposes intended for infants. CODEX STAN 72-1981. Formerly CAC/RS 72-1972. Adopted as a worldwide Standard in 1981. Amendment: 1983, 1985, 1987, 2011, 2015 and 2016. Revision: 2007. Codex Alimentarius. [Accessed on: July 22 $\left.{ }^{\text {nd }}, 2021\right]$. Available at: https: / / www.nicd.ac.za/wp-content/uploads/2018/05/ Standard_for_Infant_Formula_and_Formulas_for_ Special_Medical_Purposes_intended_for_Infant_CODEX_STAN_72-1981_formerly_CAC_RS_72-1972.pdf

6. Neville MC. The physiological basis of milk secretion. Ann N Y Acad Sci. 1990; 586:1-11.

7. Szilagyi A. Redefining lactose as a conditional prebiotic. Can J Gastroenterol. 2004; 18(3):163-7.
8. Schaafsma G. Lactose and lactose derivatives as bioactive ingredients in human nutrition. Int Dairy J. 2008; 18(5):45865.

9. Szilagyi, A. Lactose-a potential prebiotic. Aliment Pharmacol Ther. 2002; 16(9):1591-602.

10. Ziegler EE, Fomon SJ. Lactose enhances mineral absorption in infancy. J Pediatr Gastroenterol Nutr. 1983; 2(2):288-94.

11. Abrams SA, Griffin IJ, Davila PM. Calcium and zinc absorption from lactose-containing and lactose-free infant formulas. Am J Clin Nutr. 2002; 76(2):442-6.

12. EFSA Panel on Dietetic Products, Nutrition and Allergies (NDA). Scientific Opinion on the substantiation of health claims related to lactose and increase in calcium absorption leading to an increase in calcium retention(ID 668) pursuant to Article 13(1) of Regulation (EC) No 1924/2006. EFSA Journal. 2011; 9(6):2234.

13. Bertolo RFP, Bettger WJ, Atkinson SA. Divalent metals inhibit and lactose stimulates zinc transport across brush border membrane vesicles from piglets. J Nutr Biochem. 2001; 12(2):73-80.

14. Gunnerud U, Holst JJ, Östman E, Björck I. The glycemic, insulinemic and plasma amino acid responses to equicarbohydrate milk meals, a pilot- study of bovine and human milk. Nutr J. 2012; 11:83.

15. Slupsky CM, He X, Hernell O, Andersson Y, et al. Postprandial metabolic response of breast-fed infants and infants fed lactose-free vs regular infant formula: A randomized controlled trial. Sci Rep. 2017; 7(1):3640.

16. Aimutis RW. Lactose cariogenicity with an emphasis on childhood dental caries. Int Dairy J. 2012; 22(2):152-8.

17. Coelho AI, Berry GT, Rubio-Gozalbo ME. Galactose metabolism and health. Curr Opin Clin Nutr Metab Care. 2015; 18(4):422-7.

18. Prado EL, Dewey KG. Nutrition and brain development in early life. Nutr Rev. 2014; 72(4):267-84.

19. Roser M, Josic D, Kontou M, Mosetter K, et al. Metabolism of galactose in the brain and liver of rats and its conversion into glutamate and other amino acids. J Neural Transm (Vienna). 2009; 116(2):131-9.

20. Walsh C, Lane J, Sinderen D, Hickey R. Human Milk Oligosaccharides: Shaping the Infant Gut Microbiota and Supporting Health. J Funct Foods. 2020; 72:104074.

21. Turroni F, Milani C, Duranti S, Lugli GA, et al. The Infant Gut Microbiome as a Microbial Organ Influencing Host Well-Being. Ital J Pediatr. 2020; 46(1):16.

22. Milani C, Duranti S, Bottacini F, Casey E, et al. The First Microbial Colonizers of the Human Gut: Composition, Activities, and Health Implications of the Infant Gut Microbiota. Microbiol Mol Biol Rev. 2017; 81(4):e00036-17.

23. Daly K, Darby A, Hall N, Nau A, et al. Dietary supplementation with lactose or artificial sweetener enhances swine gut lactobacillus population abundance. Br J Nutr. 2014; 111 (Suppl 1):S30-5.

24. Cederlund A, Kai-Larsen Y, PrintzG, YoshioH, et al. Lactose in Human Breast Milk an Inducer of Innate Immunity with Implications for a Role in Intestinal Homeostasis. PLoS One. 2013; 8(1):e53876.

25. Lenfestey MW, Neu J. Gastrointestinal development: Implications for management of preterm and term infants. Gastroenterol Clin North Am. 2018; 47(4):773-91.

26. Shulman RJ, Schanler RJ, Lau C, Heitkemper M, et al. Early feeding, feeding tolerance, and lactase activity in preterm infants. J Pediatr. 1998; 133(5):645-9.

27. Szilagyi A, Ishayek N. Lactose intolerance, dairy avoidance, and treatment option. Nutrients. 2018; 10(12):1994.

28. Leseva M, Grand R, Klett H, Boerries M, et al. Differences in DNA Methylation and Functional Expression in Lactase Persistent and Non-persistent Individuals. Sci Rep. 2018; 
8(1):5649.

29. Wanes D, Husein D, Naim H. Congenital Lactase Deficiency: Mutations, Functional and Biochemical Implications, and Future Perspectives. Nutrients. 2019; 11(2):461.

30. Di Constanzo M, Canani R. Lactose Intolerance: Common Misunderstandings. Ann Nutr Metab. 2018; 73(suppl 4):307.

31. Savaiano DA, Ritter AJ, Klaenhammer TR, James GM, et al. Improving lactose digestion and symptoms of lactose intolerance with a novel galacto-oligosaccharide (RP-G28): A randomized, double-blind clinical trial. Nutr J. 2013; 12:160.

32. Levri KM, Ketvertis K, Deramo M, MerensteinJH, D'Amico F. Do probiotics reduce adult lactose intolerance? A systematic review. J Fam Pract. 2005; 54:613-20.
33. OakSJ, Jha R. The effects of probiotics in lactose intolerance: A systematic review. Crit Rev Food Sci Nutr. 2019; 59:167583.

34. Leis R, de Castro MJ, de Lamas C, Picáns R, Couce ML. Effects of prebiotic and probiotic supplementation on lactase deficiency and lactose intolerance: A systematic review of controlled trials. Nutrients. 2020; 12(5):1487.

35. Savaiano DA. Lactose digestion from yogurt: Mechanism and relevance. Am J Clin Nutr. 2014; 99 (Suppl 5):S1251-5.

36. Saborido R, Leis R. El yogur y recomendaciones dietéticas en la intolerancia a la lactosa. Nutr Hosp. 2018; 35(Spe 6):458.

37. Hofman DL, van Buul VJ, Brouns FJ. Nutrition, health, and regulatory aspects of digestible maltodextrins. Crit Rev Food Sci Nutr. 2016; 56(12):2091-100. 